EESTI NSV TEADUSTE AKADEEMIA TOIMETISED. XIV KOIDE FOOSIKA-MATEMAATIKA- JA TEHNIKATEADUSTE SEERIA. 1965, NR. 2

ИЗВЕСТИЯ АКАДЕМИИ НАУК ЭСТОНСКОИ ССР. ТОМ ХІV СЕРИЯ ФИЗИКО-МАТЕМАТИЧЕСКИХ И ТЕХНИЧЕСКИХ НАУК. 1965, № 2

\author{
И. КЛЕСМЕНТ, Э. ЛАГЕДА, О. ЭЙЗЕН
}

\title{
ТОНКОСЛОЙНАЯ ХРОМАТОГРАФИЯ ФЕНОЛОВ
}

За последнее время опубликовано много работ по тонкослойной хроматографии, эффективному методу разделения веществ в тонком слое адсорбента на пластинках $[1,2]$. Некоторые из этих работ посвящены качественному и полуколичественному анализам фенольных смесей. Была исследована возможность применения данного метода для разделения и идентификации несложных смесей фенолов - первых гомологов фенольного ряда, а также водорастворимых двухатомных фенолов [3-6]. Изучалось влияние структуры фенолов на их относительные длины пробега на пластинке $\left(R_{f}\right)$ на примерах разделения изомерных ксиленолов [17]. При этом выяснилось значительное сслабляющее действие ортоалкильных цепей на адсорбируемость фенолов. Опубликована работа по количественному определению фенолов, разделенных тонкослойной хроматографией [18]. Фенолы, экстрагированные из слоя, определили колориметрически. В качестве сорбента использовались силикагель [3, 5, 7], окись алюминия [16], а также смесь силикагеля и окиси алюминия $\left[{ }^{4,8}\right]$; элуентами служили различные смеси растворителей.

Целью нашей работы было проверить, можно ли применить настоящий метод при исследовании сланцевых фенолов. Последние, как и фенолы термического разложения топлива, имеют сложный, многокомпонентный состав.

Изучалась возможность разделения фенолов на близкие по свойствам группы. Для этого определили $R_{f}$ многих фенолов, среди которых были одноатомные и двухатомные, различные бициклические, а также фенолы, содержащие нейтральный кислород.

В работе использовались стеклянные пластинки размеров $12 \times 18 \mathrm{~cm}$. Адсорбентом служила малоактивная окись алюминия, содержание влаги в адсорбенте составляло $4,2 \%$. Хроматографировали на незакрепленном слое адсорбента толщиной 0,5 мм. Пластинку ставили в стеклянный кристаллизатор на щелевое устройство $\left.{ }^{2}\right]$ под углом $15^{\circ}$. Для определения $R_{f}$ по одной капле каждого фенола ( $2 \%$-ный раствор) помещали на пластинку, на расстоянии 1 см от края. Хроматографировали восходящим потоком растеорителя, элуирование прекращали после того, как фронт растворителя достигал края пластинки. После элуирования пластинки сушили несколько минут на воздухе и детектировали парами йода. Для выявления пятен применялись и другие летучие реактивы - бром, аммиак и пары олеума, но йод оказался наиболее удобным. В случае слабой окраски пятен, их рассматривали в ультрафиолетовом свете.

В качестве элуента использовались смеси относительно полярных растворителей, а также чистые растворители. В основномэто были смеси бензол + метанол и хлороформ + этилацетат. Применяемый адсорбент является высокополярным материалом, на котором фенолы легко разделяются по полярности. 
$R_{f}$ одноатомных алкилфенолов на окиси алюминия

\begin{tabular}{|c|c|c|c|}
\hline (i) 5 & \multicolumn{2}{|c|}{ Растворитель } & \multirow[b]{2}{*}{ Окраска с йодом } \\
\hline Названия фенолов & $\begin{array}{c}\text { бензол }+ \\
\text { метанол } \\
(9: 1)\end{array}$ & $\begin{array}{c}\text { хлороформ } \\
+ \text { уксусно- } \\
\text { этиловый } \\
\text { эфир }(3: 1)\end{array}$ & \\
\hline Фенол & 0,30 & 0,28 & Красно-лиловый \\
\hline 2-Метилфенол & 0,42 & 0,42 & Коричневый \\
\hline 3-Метилфенол & 0,33 & 0,32 & Синий \\
\hline 4-Метилфенол & 0,32 & 0,30 & Синий \\
\hline 2,5 -Диметилфенол & 0,46 & 0,46 & Желтый \\
\hline 3,4 -Диметилфенол & 0.37 & 0,34 & Зелено-синий \\
\hline 3,5-Диметилфенол & 0,36 & 0,38 & Слабо-желтый \\
\hline 2-Этилфенол & 0,47 & 0,52 & Коричневый \\
\hline 2-Аллилфенол & 0,46 & 0,50 & \\
\hline 2-Изопропилфенол & 0,49 & 0,58 & \\
\hline 3-Метил-5-этилфенол & 0,40 & 0,41 & Светло-коричневый \\
\hline 2,3,4-Триметилфенол & 0,50 & 0,54 & Желтый \\
\hline $2,3,5$-Триметилфенол & 0,47 & 0,56 & Желтый \\
\hline $2,4,5$-Триметилфенол & 0,46 & 0,56 & Желтый \\
\hline $2,4,6$-Триметилфенол & 0,63 & 0,77 & Желтый \\
\hline $3,4,5$-Триметилфенол & 0,34 & 0,38 & \\
\hline 2-Метил-5-изопропилфенол & 0,48 & 0,54 & Синий \\
\hline 2-Изопропил-5-метилфенол & 0,57 & 0,68 & Коричневый \\
\hline 2-н-бутилфенол & 0,59 & 0,79 & \\
\hline 4-Втор-бутилфенол & 0,40 & 0,31 & Коричневый \\
\hline 4-Трет-бутилфенол & 0,40 & 0,31 & \\
\hline $\begin{array}{l}2,4 \text {-Дивтор-бутилфенол } \\
2,4 \text {-Дитрет-бутилфенол }\end{array}$ & $\begin{array}{l}0,59 \\
0,59\end{array}$ & $\begin{array}{l}0,79 \\
0.80\end{array}$ & Желтый \\
\hline 2,4-Дитрет-оутилфенол & & 0,80 & \\
\hline
\end{tabular}

При составах растворителей бензол: метанол $(9: 1)$ и хлороформ: этилацетат $(3: 1)$ одноатомные фенолы распределяются на пластинке $\left(R_{f}=\right.$ $=0,3-0,7)$, при этом двухатомные фенолы остаются на месте. Для их перемещения следует повысить концентрацию полярного компонента в растворителе.

В табл. 1 представлены результаты разделения одноатомных, одноциклических алкилфенолов, в табл. 2 и 3 - соответственно бициклических и фенолов, содержащих нейтральный кислород. Там же отмечена окраска фенолов после прибавления йода.

Полученные данные показывают, что на распределение фенолов по пластинке количество их циклов, молекулярный вес и содержание нейтрального кислорода влияют мало. В основном на распределение в слое влияет присутствие или отсутствие алкильной группы в ортоположении, а также относительная величина такой группы.

Общеизвестно, что адсорбция полярных соединений на полярном сорбенте связана с образованием водородных связей между сорбентом и активной функциональной группой соединения. Алкильная цепь, лежащая близко к гидроксильной группе, экранирует ее, затрудняет образование водородных связей и уменьшает адсорбируемость соединения. Так называемый ортоэффект фенолов, известный при хроматографировании их на бумаге $\left[{ }^{19}\right]$, в колонке на силикагеле $\left[{ }^{10}\right]$ уже ранее исследован на тонком слое адсорбента [7, $\left.{ }^{11}\right]$. (В последних работах рассматриваются вопросы разделения изомерных ксиленолов). В соответствии с описанной теорией экранирующего действия ортоалкильных групп сильно адсорбировались диметилфенолы без ортозаместителя, среднее положение занимали фенолы с одной ортометильной группой. Слабо адсорбировался 2,6-диметилфенол, фенольная группа которого экранирована с двух сторон. 
Такая же закономерность піодмечена в настоящей работе (табл. 1) при разделении изомерных триметилфенолов.

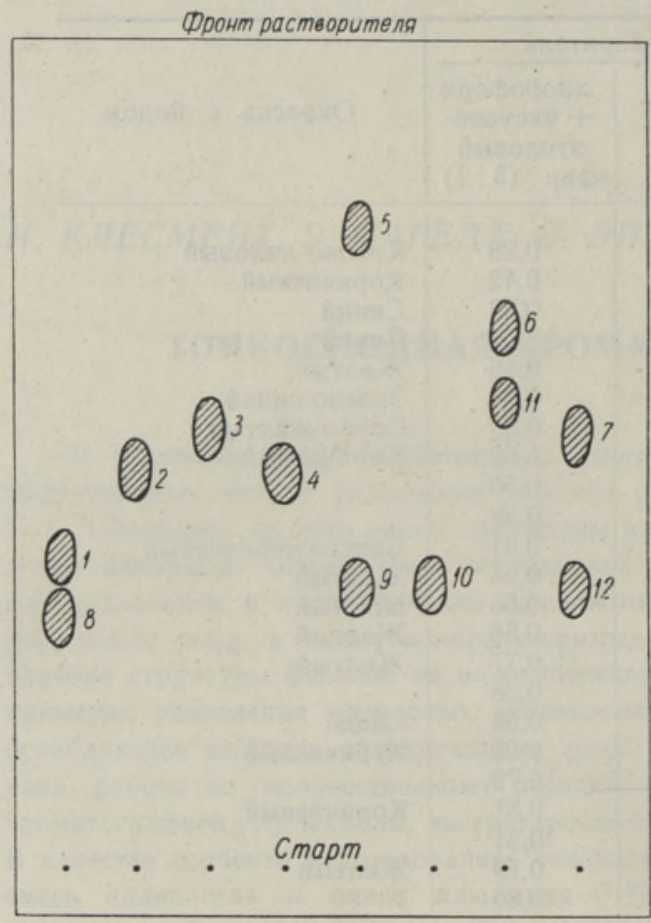

В нашем распоряжении было несколько фенолов, имеющих в качестве ортозаместителя алкильную группу разной величины и структуры. Хроматограмма этих фенолов приведена на рис. 1. Пятна фенолов расположены в порядке увеличения алкильных цепей. Основная закономерность: с увеличением 2-алкильной группы $R_{f}$ увеличивается (адсорбируемость уменьшается). Такая же закономерность отмечена при хроматографировании нескольких 2-алкильных фенолов в колонке на силикагеле [10].

Рис. 1. Хроматограмма орто- и паразамещенных фенолов. Растворитель-хлороформ+этилацетат $(3: 1): 1$ 2-метилфенол; $2-2$-этилфенол; 3 2-изопропилфенол; 4 - 2-аллилфенол; $5-2$-бутилфенол; $6-2$-циклогексилфенол; 7 - 2-бензилфенол; 8 4-метилфенол; 9 - 4-вторбутилфенол; $10-4$-трет-бутилфенол; $11-$ 4-циклогексилфенол; $12-4$-бензилфенол.

Из равномерно поднимающегося ряда $R_{f} 2$-алкилфенолов выпадают 2 -аллил- и 2-бензилфенолы, содержащие в боковых цепях двойные связи. Роль алкильных групп не органичивается только экранированием гидроксила, в присутствии ненасыщенных связей они также адсорбируются. На рис. 1 представлены, кроме того, результаты хроматографирования разных 4-алкильных фенолов. Влияние ненасыщенных связей можно наблюдать на фенольной паре 4-циклогексилфенол-4-фенилфенол, причем последний задерживается значительно больше, чем первый.

Изучению зависимости величины $R_{f}$ гомологических рядов фенолов от количества углеродных атомов в 4-алкильных цепях посвящена одна работа $\left[{ }^{12}\right]$. По нашим данным с увеличением 4-алкильной цепи адсорбируемость фенолов уменьшается, но по сравнению с ортоэффектом это явление незначительно (рис. 1 ). По данным табл. $1, R_{f}$ фенолов без ортозаместителя независимо от количества, величины и расположения алкильных групп лежат в пределах $0,30-0,40$ (растворитель - бензол-метанол). У фенолов с одной 2 -метильной группой $R_{f}=0,42-0,50$, при увеличении ортозаместителя этот показатель выше. При использовании в качестве растворителя смеси хлороформ-этилацетат селективность разделения этих структурных групп еще выше.

В табл. 2 представлены $R_{f}$ некоторых одноатомных бициклических фенолов. Их повышенная по сравнению с одноядерными фенолами полярность обуславливает уменьшение их $R_{f}$, но отличие слишком мало для разделения обеих групп фенолов. В основном величина $R_{f}$ зависит от присутствия или отсутствия ортозаместителей.

Если фенол содержит нейтральный кислород, то, как показывают данные табл. 3, адсорбируемость его зависит также от функџии этого кисло- 
Таблица 2

\section{$R_{f}$ бициклических одноатомных фенолов на окиси алюминия}

\begin{tabular}{|c|c|c|c|}
\hline \multirow[b]{2}{*}{ Названия фенолов } & \multicolumn{2}{|c|}{ Растворитель } & \multirow[b]{2}{*}{ Окраска с йодом } \\
\hline & $\begin{array}{c}\text { бензол }+ \\
\text { метанол } \\
(9: 1)\end{array}$ & $\begin{array}{c}\text { хлороформ } \\
+ \text { уксусно- } \\
\text { этиловый } \\
\text { эфир }(3: 1)\end{array}$ & \\
\hline $\begin{array}{l}\text { 5-Инданол } \\
\text { 2-Циклогексилфенол } \\
\text { 4-Циклогексилфенол } \\
\text { 4-Фенилфенол } \\
\text { 2-Бензилфенол } \\
\text { 4-Бензилфенол } \\
\text { 1-Нафтол } \\
\text { 2-Нафтол }\end{array}$ & $\begin{array}{l}0,32 \\
0,56 \\
0,40 \\
0,28 \\
0,54 \\
0,31 \\
0,33 \\
0,30\end{array}$ & $\begin{array}{l}0,35 \\
0,68 \\
0,38 \\
0,33 \\
0,57 \\
0,37 \\
0,35 \\
0,32\end{array}$ & $\begin{array}{l}\text { Коричневый } \\
\text { Коричневый }\end{array}$ \\
\hline
\end{tabular}

Таблица 3

$R_{f}$ фенолов, содержащих нейтральный кислород, на окиси алюминия

\begin{tabular}{|c|c|c|c|}
\hline \multirow[b]{2}{*}{ Названия фенолов } & \multicolumn{2}{|c|}{ Растворитель } & \multirow[b]{2}{*}{ Окраска с йодом } \\
\hline & $\begin{array}{c}\text { бензол }+ \\
\text { метанол } \\
(9: 1)\end{array}$ & $\begin{array}{l}\text { хлороформ } \\
\text { † уксусно- } \\
\text { этиловый } \\
\text { эфир }(3: 1)\end{array}$ & \\
\hline $\begin{array}{l}\text { 2-Метоксифенол } \\
\text { 2-Метокси-4-метилфенол } \\
\text { 2-Трет-бутил-4-метокси- } \\
\text { фенол } \\
\text { 3-Метил-6-оксикумарон } \\
\text { 4-Оксиацетофенон } \\
\text { 4-Оксипропиофенон } \\
\text { 4-Оксибензофенон }\end{array}$ & $\begin{array}{l}0,46 \\
0,49 \\
0,58 \\
0,36 \\
0,26 \\
0,29 \\
0,10\end{array}$ & $\begin{array}{c}0,20 \\
0,26 \\
0,70 \\
0,20 \\
0,10 \\
0,15 \\
\text { На месте }\end{array}$ & $\begin{array}{l}\text { Розовый } \\
\text { Синий } \\
\text { Желтый } \\
\text { Зеленый } \\
\text { Желтый } \\
\text { Желтый } \\
\text { Желтый }\end{array}$ \\
\hline
\end{tabular}

таблица 4

$R_{f}$ двухатомных фенолов на окиси алюминия

\begin{tabular}{|c|c|c|c|}
\hline \multirow[b]{2}{*}{ Названия фенолов } & \multicolumn{2}{|c|}{ Растворитель } & \multirow[b]{2}{*}{ Окраска с йодом } \\
\hline & $\begin{array}{c}\text { бензол }+ \\
\text { метанол } \\
(8: 2)\end{array}$ & $\begin{array}{c}\text { уксусно- } \\
\text { этиловый } \\
\text { эфир }\end{array}$ & \\
\hline $\begin{array}{l}\text { 1,2-Диоксибензол } \\
1,3-\text { Диоксибензол } \\
\text { 1,4-Диоксибензол } \\
\text { 1,3-Диокси-2-метилбензол } \\
\text { 1,3-Диокси-5-метилбензол } \\
\text { 1,3-Диоксинафталин } \\
\text { 1,5-Диоксинафталин } \\
\text { 1,7-Диоксинафталин } \\
\text { 2,3-Диоксинафталин } \\
\text { 2,7-Диоксинафталин } \\
\text { 2,2-Диоксидифенил } \\
\text { 4,4-Диоксидифенил }\end{array}$ & $\begin{array}{c}\text { На месте } \\
0,34 \\
0,40 \\
0,48 \\
0,44 \\
0,32 \\
0,39 \\
0,44 \\
\text { На месте } \\
0,36 \\
0,20 \\
0,30\end{array}$ & $\begin{array}{c}\text { На месте } \\
0,20 \\
0,25 \\
0,72 \\
0,12 \\
0,05 \\
0,20 \\
0,17 \\
\text { Ha месте } \\
0,15 \\
0,10 \\
0,20\end{array}$ & $\begin{array}{l}\text { Синий } \\
\text { Лиловый } \\
\text { Желтый } \\
\text { Коричневый } \\
\text { Лиловый } \\
\text { Оранжевый } \\
\text { Красно-лиловый } \\
\text { Лиловый } \\
\text { Желтый } \\
\text { Зеленый } \\
\text { Желтый } \\
\text { Коричневый }\end{array}$ \\
\hline
\end{tabular}

рода. Присутствие метоксильных групп в ортоположениях тоже уменьшает адсорбируемость, но карбонильная группа, наоборот, обуславливает увеличение адсорбируемости фенолов. 
С полярным растворителем бензол-метанол метоксифенолы довольно подвижны и не отделяются от других групп фенолов, но с растворителем хлороформ-этилацетат их $R_{f}$ низкие. По данным табл. 1 и 2 алкилфенолы и двухядерные фенолы с последним растворителем имеют высокие $R_{f}$, что дает возможность отделить их от фенолов, содержащих нейтральный кислород.

В табл. 4 представлены $R_{f}$ ряда двухатомных фенолов. Необходимо отметить, что на окиси алюминия одноатомные фенолы отделяются от двухатомных легче, чем на силикагеле. Это обуславливается, вероятно, более щелочными свойствами окиси алюминия. Замечено также, что фенолы с близколежащими гидроксильными группами имеют $R_{f}$ меньше, чем другие фенолы с таким же углеродным скелетом.

При аналитической работе, кроме качественных данных, желательно получить количественные результаты. Проведены опыты по колориметрическому определению фенолов после их экстрагирования из слоя $\left[{ }^{5}, 8\right]$. В настоящей работе изучалась зависимость величины поверхности пятна от количества вещества. Этот метод уже применяли для приблизительного количественного определения некоторых веществ [13]. Установлено, что между логарифмом концентрации вещества и величиной пятна существует линейная зависимость.

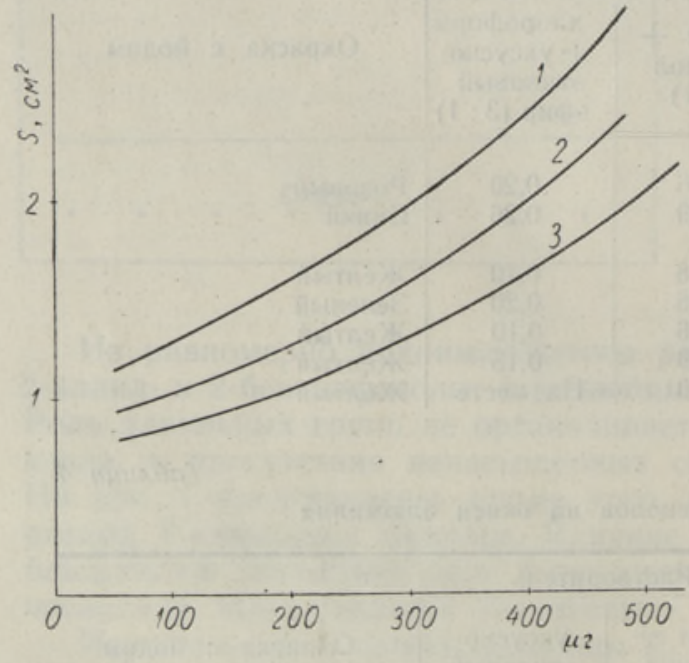

Рис. 2. Зависимость величины пятна от количества вещества и $R_{f}$. Растворитель - бензол+метанол $(9: 1), 1-2,4,6$-триметилфенол, $R_{f}=0,63 ; 2-2$-этилфенол, $R_{f}=0.47$; 3 - фенол, $R_{f}=0,30$.

При проведении опытов калиброванным стеклянным капилляром на пластинку наносились равные объемы растворов, йеющих разные концентрации. После обычного процесса хроматографирования поверхности пятен измеряли планимером. Результаты опытов с некоторыми фенолами представлены на рис. 2. Кривые зависимости величины пятна от количества вещества имеют форму, близкую к логарифмической. Установлено, что у большинства фенолов эти калибровочные кривые не совпадают. При равных количествах вещества с увеличением $R_{f}$ поверхности пятен увеличиваются, что можно наблюдать на рис. 2. Но это правило не распространяется на все фенюлы. Встречается много фенолов, у которых-калибровочные кривые не соответствуют величине их $R_{f}$. В связи с этим при количественном определении необходимо иметь для каждого индивидуального фенола калибровочную кривую.

Вторая трудность возникает при совпадении пятен. Вычеркивались калибровочные кривые для $3,4,5-$, 2,4,5- и 2,4,6-триметилфенолов, которые располагаются в последовательности их $R_{f}$. После прибавления к каждой пробе 2,3,5-триметилфенола в количестве, равном количеству 2,4,5-триметилфенола, вновь вычерчивались калибровочные кривые. Так как $R_{f}$ обоих фенолов близки, их пятна совпадали. Выяснилось, что после удвоения количества фенола в пятне, его размеры мало увеличивались, фенолы не вытесняли друг друга.

Хотя расчет количеств по величинам поверхностей пятен очень прост, 


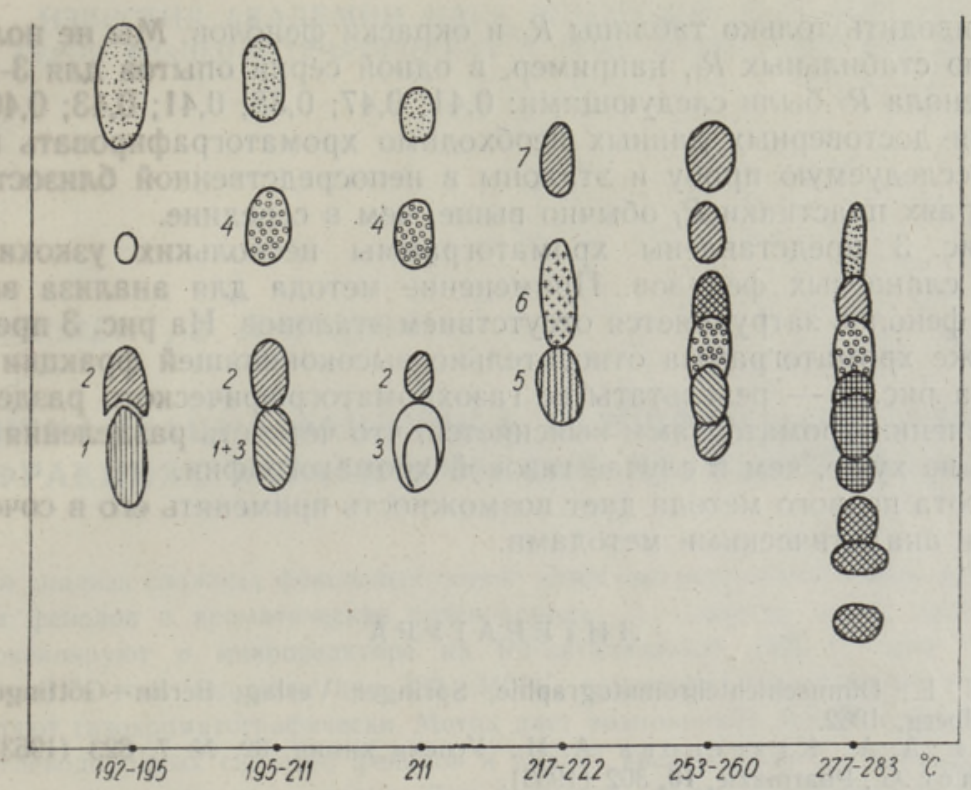

Рис. 3. Хроматограммы фракций сланцевых фенолов. Растворитель - бензол+метанол $(9: 1): 1$ - фенол; 2 - 2-метилфенол; 3 - 3- и 4-метилфенол; 4 - 2-этилфенол; 5 - 3,4-диметилфенол; 6 - 2,5-диметилфенол; 7 - 2,4,6-триметилфенол.

вышеописанные недостатки уменьшают точность метода и делают его применение возможным только для несложных смесей.

Проведенные опыты показали, что методом тонкослойной хроматографии фенолы разделяются по их полярности. Двухатомные отделяются от других легко, разделение алкилфенолов в основном характеризует ортоэффект. Фенолы с 2-заместителем отделяются от других изомеров, а особенно высокий $R_{f}$ указывает на экранирование с двух сторон или на присутствие многоатомной 2-алкильной цепи.

Вопрос группового разделения различных алкилфенолов сложнее. Присутствие второго циклла в молекуле фенола и ароматический характер последнего уменьшают $R_{f}$ соединения, а насыщенные боковые цепи, наоборот, повышают его. Однако различие $R_{f}$ слишком мало для разделения одно- и бициклических фенолов. В основном метод пригоден для идентификации индивидуальных фенолов. Но в отличие от газовой хроматографии здесь недоста-

Рис. 4. Хроматограмма фракции фенолов 277 $283^{\circ} \mathrm{C}$, полученная при помощи газохроматографического разделения. Условия хроматографирования; длина колонки - $1,2 \mathrm{M}$; СЖФ - апиезон L, $15 \%$ от веса хромосорба $\mathrm{W}$; температура $-175^{\circ} \mathrm{C}$; расход аргона 45 мл/мин; давление - 0,18 атм.

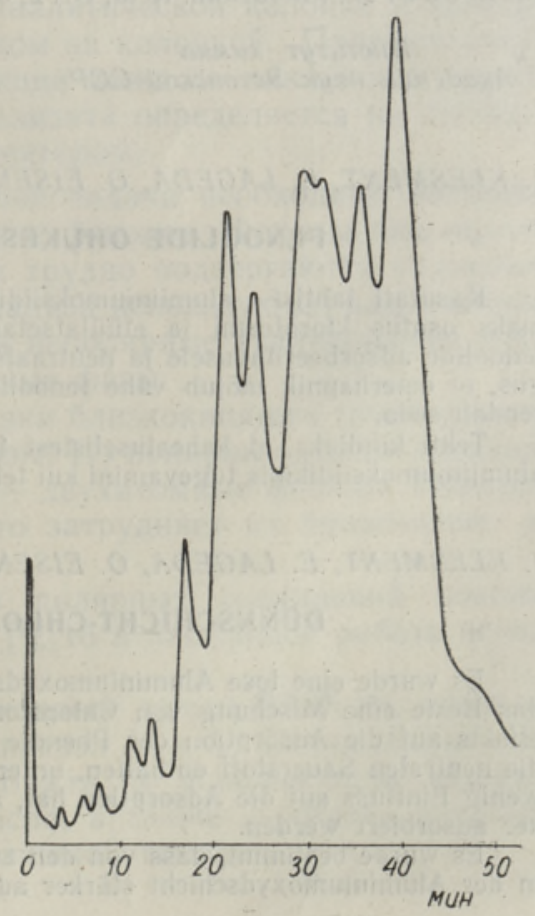


точно приводить только таблицы $R_{f}$ и окраски фенолов. Мы не получили полностью стабильных $R_{f}$, например, в одной серии опытов для 3 -метил-5-этилфенола $R_{f}$ были следующими: 0,$41 ; 0,47 ; 0,38 ; 0,41 ; 0,43 ; 0,40$. Для получения достоверных данных необходимо хроматографировать параллельно исследуемую пробу и эталоны в непосредственной близости, так как на краях пластинки $R_{f}$ обычно выше, чем в середине.

На рис. 3 представлены хроматограммы нескольких узкокипящих фракций сланцевых фенолов. Применение метода для анализа высококипящих фенолов затрудняется отсутствием эталонов. На рис. 3 представлена также хроматограмма относительно высококипящей фракции $277-$ $283^{\circ}$, а на рис. 4 - результаты ее газохроматографического разделения. При сравнении хроматограмм выясняется, что четкость разделения в тонком слое не хуже, чем в случае газовой хроматографии.

Простота первого метода дает возможность применять его в сочетании с другими аналитическими методами.

\section{ЛИТЕРА Т У Р А}

1. Stahl E., Dünnschichtchromatographie, Springer Verlag. Berlin-Göttingen-Heidelberg, 1962.

2. Ахрем А. А., Кузнец в в А. И., Успехи химии, 32, № 7, 823 (1963).

3. W a g n e r G., Pharmazie, 10, 302 (1955).

4. S e e b o th H., Chem. Techn., 15, Nr. 1, 34 (1963).

5 . Л и п и н а Т. Г., Труды по химии и химической технологии № 2 , Гос. ун-тет им. Н. А. Лобачевского, Горький, 1962, с. 424.

6. Хей фиц Л. А., Молдованска я Г. И., Шулов Л. М., Ж. анал. химии, 18, № 2, 267 (1963).

7. Petrow it z H. J., Erdöl u. Kohle, 14, Nr. 11, 923 (1961).

8. Se eb oth H., Gor sch H., Chem. Techn. 15, Nr. 5, 294 (1963)

9. Grebenovsk y E., Coll. Czech. Chem. Commun., 28, Nr. 10, 2813 (1963).

10. C a r 1 t o n J. K., J. Amer. Chem. Soc., 78, Nr. 3, 1069 (1956).

11. Pastuska G., Petrowitz H. J., Chemiker-Ztg., 86, Nr. 9, 311 (1962).

12. Halmekoski J., H a n n i k a in e n H., Suomen Kemistilehti, B36, Nr. 2, 24 (1963).

13. S e he r A., Microchim. Acta, Nr. 2, 308 (1961).

\section{Институт химии \\ Академии наук Эстонской ССР \\ Поступила в редакцию 15/VIII 1964}

\section{KLESMENT, E. LAGEDA, O. EISEN}

\section{FENOOLIDE OHUKESEKIHILINE KROMATOGRAAFIA}

Kasutati lahtist alumiiniumoksiidikihti ja mitmesuguseid lahustajaid, millest parimaks osutus kloroformi ja etüülatsetaadi segu vahekorras $3: 1$. Uuriti ortoefekti mōju fenoolide adsorbeeritavusele ja neutraalset hapnikku sisaldavate fenoolide lahutamist. Selgus, et eeterhapnik mōjub vähe fenoolide adsorptsioonile, kuid karbonüülne hapnik suurendab seda.

Tehti kindlaks, et kahealuselistest fenoolidest adsorbeeritakse 1,2-dihüdroksüderivaate alumiiniumoksiidikihis tugevamini kui teisi isomeere.

\section{KLESMENT, E. LAGEDA, O. EISEN}

\section{DONNSCHICHT-CHROMATOGRAPHIE DER PHENOLE}

Es wurde eine lose Aluminiumoxydschicht benutzt und mehrere Lösemittel, von denen das Beste eine Mischung von Chloroform und Ethylacetat war. Der Einfluss des Orthoeffekts auf die Adsorption der Phenole wurde bestimmt und die Verteilung der Phenole, die neutralen Sauerstoff enthalten, untersucht. Die Resultate ergaben, dass Åthersauerstoif wenig Einfluss auf die Adsorption hat, aber die Phenole mit Karbonylsauerstoff weit stärker adsorbiert werden.

Es wurde bestimmt, dass von den zweiwertigen Phenolen 1,2-Dihydroxydverbindungen in der Aluminiumoxydschicht stärker adsorbiert werden als andere Isomere. 